\title{
SISTEM INFORMASI PEMBAYARAN UANG SEKOLAH DENGAN MODEL MVC DAN MENGGUNAKAN NOTIFIKASI SMS GATEWAY
}

\author{
Dwi Cita Septia Candra', Lutfi Syafirullah ${ }^{2}$, Muhammad Nur Faiz ${ }^{3}$ \\ ${ }_{1,2,3}$ Teknik Informatika, Politeknik Negeri Cilacap \\ Jl Dokter Soetomo No.1 Sidakaya, Cilacap, Jawa Tengah, Indonesia
}

Email : citacandra4@gmail.com ${ }^{1}$, syafirullah.lutfi@gmail.com², faiz@pnc.ac.id ${ }^{3}$

\begin{abstract}
The Tuition Payment Information System was designed because at this time the payment of tuition at SMP Islam Cilacap still uses the general ledger, causing inaccuracies in payment data by employees (administrative). The purpose of this research is to help solve problems in the processing of tuition payment data, making payment data reports, searching payment data, knowing payment data information, and knowing the school money payment report. The system is designed using MVC (Model-View-Controller) architecture and SMS Gateway notifications as well as system development methods using System Development Life Cycle (SDLC) with Waterfall model. In addition, the system design uses PHP and HTML programming languages, database management is MYSQL and uses the Laravel framework. Based on the results of the system test and the results of the questionnaire by 10 respondents that $14 \%$ stated enough, $44 \%$ stated well and $42 \%$ stated very well calculated by the calculation of the Likert scale of $86 \%$ entered the excellent qualification which means successful. So it can be concluded that this system can solve existing problems by facilitating the processing of payment data, assisting in the creation of school money payment reports, helping in speeding up the search for payment data, knowing the payment information of tuition without having to come to school, and knowing the payment data report quickly without having to go through a long recap process.
\end{abstract}

Keyword: Information Systems, MVC, Payment, SDLC, SMS Gateway.

\section{PENDAHULUAN}

Perkembangan teknologi pada era globalisasi ini khususnya dalam bidang komputerisasi berkembang sangat pesat, sehingga peranan komputer sangat membantu dalam menyelesaikan berbagai pekerjaan. Pemanfaatan teknologi informasi di bidang pendidikan, khususnya instansi sekolah sangat dibutuhkan agar sekolah mampu mengikuti perkembangan jaman. Berbagai program yang ada di sekolah bisa dikembangkan menjadi sistem yang kinerjanya dibantu dengan perangkat komputer. Salah satu program sekolah yang dapat dikembangakan yaitu sistem informasi pembayaran uang sekolah (Witanto \& Solihin, 2016).

SMP Islam Cilacap merupakan salah satu lembaga pendidikan sekolah menengah pertama yang berdiri tahun 1951 dan beralamat di Jalan Dokter Radjiman No.95 A, Kecamatan Cilacap Tengah, Kabupaten Cilacap (Kemdikbud 
RI, 2019). SMP Islam Cilacap memiliki status akreditasi A sejak tahun 2014 dan memiliki jumlah siswa yang dari tahun ke tahun bertambah. Data siswa dari 5 tahun terakhir, siswa di SMP Islam Cilacap naik per tahun pelajaran baru.

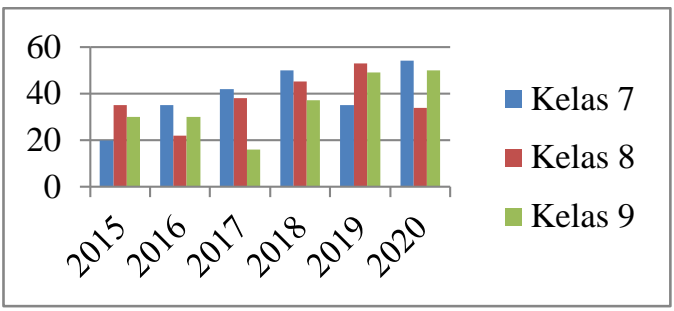

Gambar 1 Data Siswa

Gambar 1 menunjukkan bahwa data siswa yang masuk SMP Islam Cilacap terus meningkat. Tahun 2015 memiliki 85 siswa yang terdiri dari 20 siswa kelas VII, 35 siswa kelas VIII dan 30 siswa kelas IX. Tahun 2016 memiliki 87 siswa yang terdiri dari 35 siswa kelas VII, 22 siswa kelas VIII dan 30 siswa kelas IX. Tahun 2017 memiliki 96 siswa yang terdiri dari 42 siswa kelas VII, 38 siswa kelas VIII dan 16 siswa kelas IX. Tahun 2018 memiliki 132 siswa yang terdiri dari 50 siswa kelas VII, 45 siswa kelas VIII dan 37 siswa kelas IX. Tahun 2019 memiliki 137 siswa yang terdiri dari 35 siswa kelas VII, 53 siswa kelas VIII dan 49 siswa kelas IX. Tahun 2020 memiliki 138 siswa yang terdiri dari 54 siswa kelas VII, 34 siswa kelas VIII dan 50 siswa kelas IX. Jumlah keseluruhan sebanyak 675 siswa. Presentase kenaikan jumlah siswa dari tahun 2015 sampai 2020 yaitu sebesar $16.715 \%$.

Seiring bertambah siswa, proses pembayaran uang sekolah di SMP Islam Cilacap masih menggunakan sistem manual atau paper base. Sistem ini menimbulkan masalah yang dialami oleh beberapa pihak. Pada karyawan Tata Usaha (TU) berupa proses pengelolaan data pembayaran uang sekolah yang masih menggunakan buku besar menyebabkan lamanya proses pembayaran dan lamanya pencarian data pembayaran, serta pembuatan laporan yang masih menggunakan buku menyebabkan ketidakakuratan data. Pada Kepala Sekolah menemui permasalahan berupa akses untuk mengetahui laporan pembayaran uang sekolah membutuhkan waktu lama yang harus melalui beberapa tahapan oleh petugas TU. Selain itu, permasalahan lain juga dirasakan oleh orang tua siswa dalam hal penyampaian informasi pembayaran uang sekolah yang masih dilakukan secara konvensional menggunakan kartu yang terkadang informasi pembayaran yang 
sudah dilakukan tidak ditulis oleh petugas TU menimbulkan kesalahpahaman diantara kedua belah pihak dan petugas TU harus melakukan pengecekan data kembali. Sehingga sistem manual atau paper base ini dinilai kurang efektif.

Oleh karena itu, dibangun "Sistem Informasi Pembayaran Uang Sekolah dengan Model MVC dan Menggunakan Notifikasi SMS Gateway". Tujuan dibangunnya sistem ini adalah untuk membantu petugas tata usaha agar lebih mudah dalam melakukan proses pengolahan pembayaran uang sekolah, mempermudah kepala sekolah dalam melihat laporan pembayaran sekolah, dan mempermudah orang tua/wali siswa mengetahui informasi pembayaran uang sekolah.

\section{TINJAUAN PUSTAKA}

Beberapa penelitian yang relevan digunakan oleh penulis sebagai batasan penelitian dalam membangun sistem infromasi pembayaran uang sekolah ini. Beberapa penelitian tersebut antara lain : penelitian pada tahun 2017 dengan judul "Pemanfaatan Model-View-Controller (MVC) Dalam Rancang Bangun Sistem Informasi Rakornas Aptikom 2017'. Sistem ini dikembangkan dengan menggunakan arsitektur Model-View-Controller (MVC). Manfaat dari sistem ini yaitu mempermudah bertukar informasi secara on-line antar mahasiswa, dosen, peneliti, guru besar dan praktisi IT (Dayat \& Angriani, 2017).

Penelitian lainnya dengan judul "Perancangan Sistem Informasi Pengolahan Administrasi Keuangan Sekolah Menengah Pertama Islam Terpadu Assalam Garut”. Sistem ini bertujuan untuk membantu pihak sekolah khususnya staf tata usaha dalam melakukan proses pendataan siswa baru dan transaksi pembayaran bagi siswa yang telah membayar. Sistem ini menggunakan metode pengembangan USDP (Unified Software Development Process) karena metode ini berorientasi objek yang berukuran besar dan kompleks. Manfaat dari sistem informasi ini yaitu mempermudah petugas dalam transaksi pembayaran SPP (Nugraha \& Setiawan, 2017).

Penelitian selanjutnya pada tahun 2020 dengan judul "Perancangan Sistem Informasi Pembayaran SPP Berbasis Desktop Menggunakan Visual Basic". Sistem ini digunakan untuk melakukan proses administrasi pembayaran SPP lebih efisien dan dapat membuat laporan secara otomatis. Sistem ini berbasis desktop 
menggunakan metode pengembangan RAD (Rapid Application Development) karena model ini bertingkat yang menekankan siklus pembangunan pendek, singkat, dan cepat. Manfaat yang didapat dari sistem informasi ini yaitu proses administrasi pembayaran spp lebih efisien serta pembuatan laporan lebih cepat (Wiyatno et al., 2020).

Penelitian yang akan dilakukan memiliki perbedaan dengan penelitianpenelitian sebelumnya. Perbedaan tersebut diantaranya dapat menginformasikan tagihan pembayaran uang sekolah kepada orang tua/wali siswa dengan mengirimkan SMS. Sistem yang dibuat berbasis web agar mempermudah karyawan tata usaha dalam pengelolaan pembayaran uang sekolah dan penyampaian laporan pembayaran pembayaran uang sekolah kepada kepala sekolah. Tahap pengembangan sistem informasi ini berarsitektur MVC (ModelView-Contoller) dengan menerapkan metodologi SDLC (System Development Life Cycle) model Waterfall yang dibangun menggunakan bahasa pemrograman PHP (Hypertext Preprocessor) dan MySQL sebagai aplikasi database dengan penambahan fitur notifikasi SMS Gateway.

Sistem informasi merupakan komponen dari organisasi maupun prosedur organisasi yang melibatkan banyak stakholder yang dapat digunakan untuk memberikan informasi bagi pengambil keputusan dengan kebutuhan yang diperoleh dari dalam organisasi maupun dari luar organsasi (Chasanah et al., 2021). Suatu informasi memiliki kualitas yang harus dipenuhi yaitu berupa manfaat yang sangat dibutuhkan dari informasi tersebut bagi pengguna, seluruh infromasi yang digunakan benar adanya, dan infromasi yang dibutuhkan tersampaikan dengan tepat waktu. Selain itu, sistem informasi harus memiliki karakteristik seperti komponen sistem, batasan sistem, lingkungan luar sistem, penghubung sistem, masukan sistem, keluaran sistem, pengolahan sistem dan sasaran sistem itu sendiri (Al-Bahra bin Ladjamudin, 2013).

Pembayaran atau sistem pembayaran merupakan sistem yang mencakup seperangkat aturan, lembaga, dan mekanisme yang dipakai untuk melaksanakan pemindahan dan guna memenuhi suatu kewajiban yang timbuk dari suatu kegiatan ekonomi (Bank Sentral Republik Indonesia, 2020). Uang sekolah merupakan biaya yang dibebankan kepada siswa untuk membantu lembaga pendidikan 
memperlancar proses belajar mengajar dengan pembayaran yang berbeda setiap angkatan (Ma'rifati, 2015).

Model MVC (Model-View-Controller) merupakan arsitektur yang memisahkan aplikasi berdasarkan komponen utama yang membangun sebuah aplikasi tersebut (Yesputra, Rolly, Marpaung Nasrun, 2018). Model MVC ini mampu mengembangkan sebuah aplikasi maupun website secara efektif dan efisien yang dilihat dari sudut pandang pengembangan, pembagian tugas, dokumentasi, pengujian dan pemeliharaan (Riana et al., 2018). Dalam membangun sebuah aplikasi menggunakan model MVC harus memperhatikan komponen utamanya berupa model yang digunakan sebagai struktur data, view yang digunakan sebagi implementasi user interface dengan melibatkan komponen grafis yang menyediakan representasi proses internal aplikasi dan menuntun alur interaksi user terhadap aplikasi, dan controller yang bertanggung jawab terhadap perantara dari Model dan View dan semua sumber yang dibutuhkan untuk memproses permintaan HTTP (Tanjung, 2016).

\section{METODE PENELITIAN}

Dalam perancangan sistem ini menggunakan metode pengumpulan data yang digunakan untuk mendapatkan informasi yang dibutuhkan dalam penelitian sebagai berikut :

\section{Teknik Pengumpulan Data}

Teknik pengumpulan data merupakan kegiatan yang dilakukan untuk memperoleh data dengan tujuan dan kegunaan tertentu (Sugiyono, 2013). Teknik pengumpulan data yang digunakan dalam perancangan sistem ini adalah:

\section{Metode Observasi}

Penulis memperoleh data dengan melakukan pengamatan dan pengumpulan data yang dilakukan secara langsung terhadap kegiatan yang dilakukan langsung oleh petugas Bagian Tata Usaha di SMP Islam Cilacap.

2. Metode Wawancara

Wawancara yang dilakukan melalui tatap muka dan tanya jawab langsung antara pewawancara kepada pegawai Bagian Tata Usaha SMP Islam Cilacap. 
3. Metode Studi Pustaka

Pengumpulan data dengan mengadakan studi penelaahan terhadap bukubuku, literatur-literatur, catatan-catatan, dan laporan-laporan yang ada hubungannya dengan topik penelitian.

\section{Teknik Analisis Data}

Metode pengembangan sistem yang digunakan yaitu menggunakan metode SDLC (System Development Life Cycle) model Waterfall. Model Waterfall adalah model yang membangun perangkat lunak berdasarkan SDLC (System Development Life Cycle), yaitu model yang mempunyai struktur yang dimulai dari Perencanaan, Analisis, Desain dan Implementasi (Febriyati et al., 2020). Metode ini menggambarkan pendekatan yang cukup sistematis juga berurutan pada pengembangan software (Pressman \& Maxim, 2019). Tahapan-tahapan dari metode SDLC yaitu Requirements Definition, System and Software Design, Implementation and Unit Testing, Integration and System Testing, dan yang terakhir Operation and Maintenance

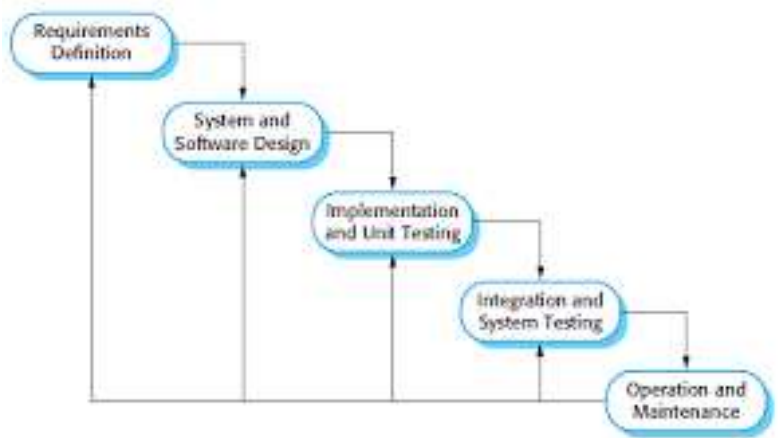

Gambar 2 Teknik Analisis Data SDLC (System Development Life Cycle) model Waterfall (Pressman \& Maxim, 2019)

\section{HASIL DAN PEMBAHASAN}

Dalam merancang serta mengelola data pembayaran uang sekolah di SMP Islam Cilacap menjadi terkomputerisasi dengan pembuatan diagram alur sistem yang dirancang menggunakan flowchart. 


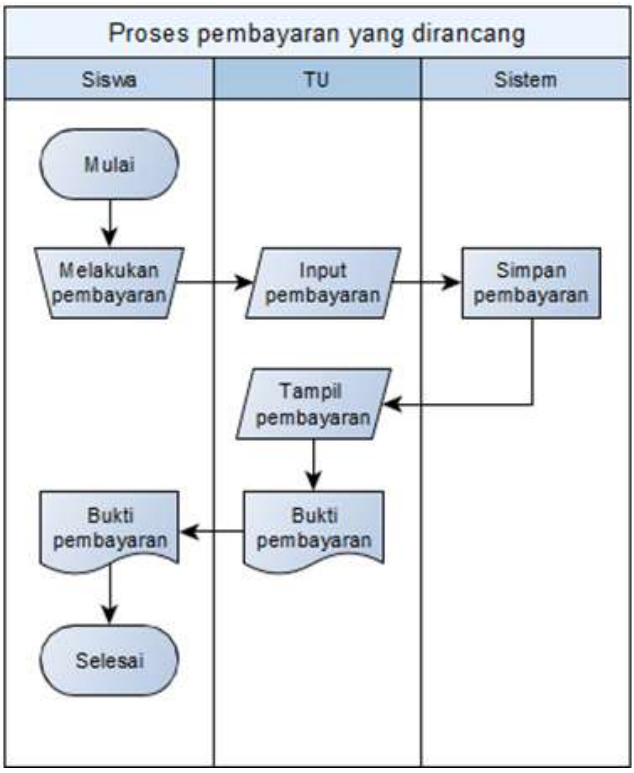

Gambar 3 Flowchart sistem pembayaran yang dirancang

Gambar 4 menjelaskan alur proses pembayaran yang dirancang adalah siswa melakukan pembayaran dengan membawa kartu pembayaran dan uang pembayaran lalu diberikan kepada karyawan Tata Usaha (TU). Karyawan TU menerima data pembayaran kemudian memasukan data pembayaran. Sistem melakukan simpan data pembayaran. Setelah itu, karyawan TU akan tampil data pembayaran yang telah disimpan tadi pada layar PC. Selanjutnya karyawan TU akan mencetak bukti pembayaran. Siswa akan mendapatkan bukti pembayaran dari karyawan TU.

Detail penjelasan perancangan komputerisasi dalam pembangunan sistem informasi pembayaran uang sekolah dengan menggunakan UML berupa Use Case Diagram. Selain itu, perancangan sistem dilengkapi dengan ERD (Entity Relationship Diagram).

\section{Use Case Diagram}

Use Case Diagram digunakan untuk menggambarkan secara ringkas siapa yang menggunakan sistem dan apa saja yang bisa dilakukannya (A.S. \& Shalahudin, 2015). 


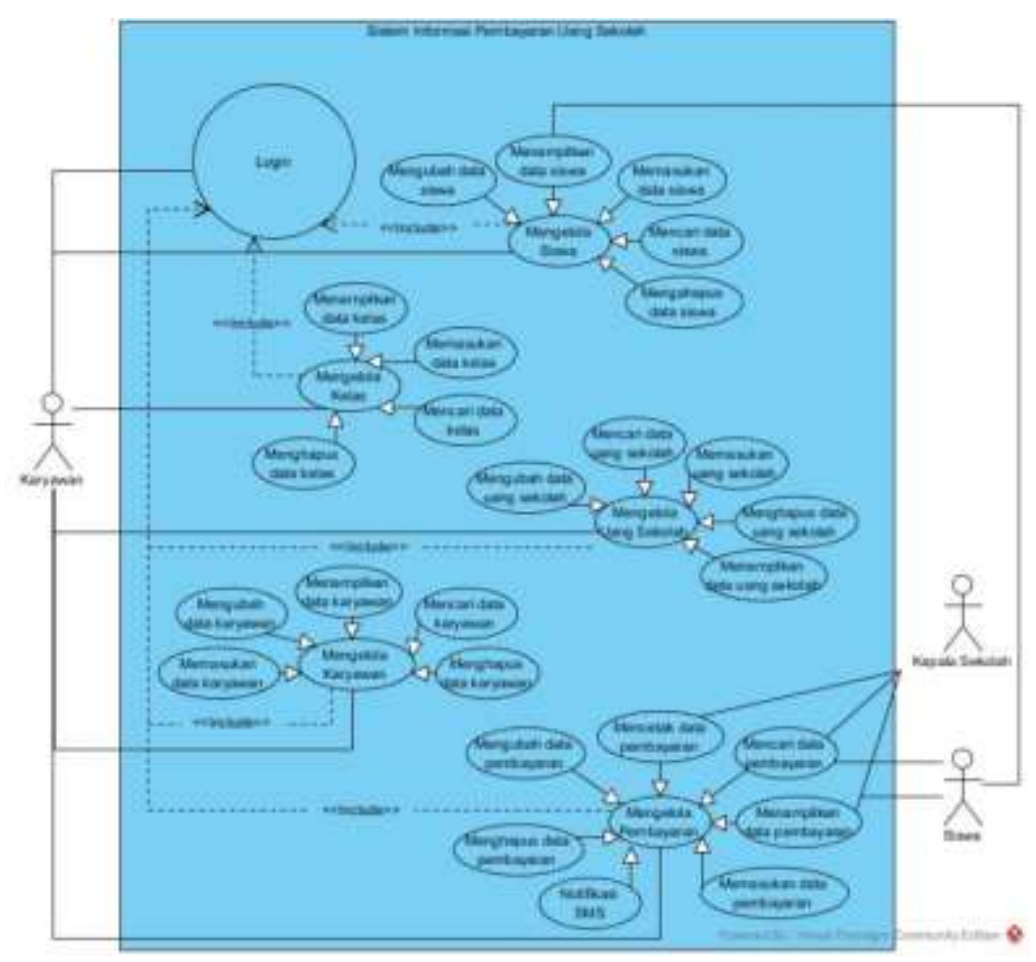

Gambar 4 Use Case Diagram

Penjelasan mengenai use case diagram Sistem Informasi Pembayaran Uang Sekolah di SMP Islam Cilacap sebagai berikut :

1. Sebelum menggunakan sistem Karyawan (Petugas Tata Usaha), Kepala sekolah, dan Orang tua siswa atau siswa harus login terlebih dahulu.

2. Karyawan TU dapat melakukan beberapa proses berupa mengelola data karyawan, mengelola data siswa, mengelola data kelas, mengelola data uang sekolah, mengelola pembayaran uang sekolah, membuat laporan data pembayaran.

3. Kepala sekolah dapat melakukan proses yaitu melihat laporan data pembayaran uang sekolah, mencari data pembayaran uang sekolah, dan mencetak data pembayaran uang sekolah.

4. Orang tua siswa atau siswa dapat melakukan lihat data pembayaran.

\section{ERD (Entity Relationship Diagram)}

ERD merupakan model visual yang banyak digunakan untuk menggambarkan entitas bisnis, atributnya, dan hubungannya satu sama lain (Gupta et al., 2021). Perancangan ERD dari sistem informasi pembayaran uang sekolah ini terdapat entitas, relasi, atribut, atribut kunci primer dan asosiasi (Rashkovits \& Lavy, 2021). 


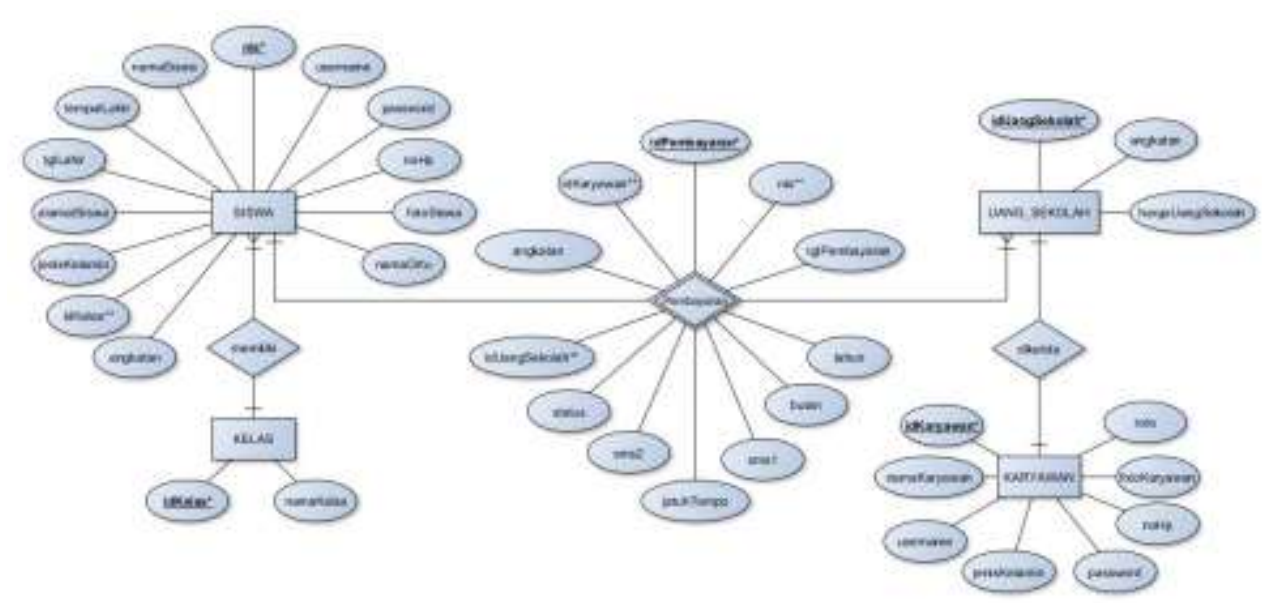

Gambar 5 ERD (Entity Relationship Diagram)

Gambar 5 menjelaskan ERD Sistem Informasi Pembayaran Uang Sekolah yang memiliki beberapa entitas yang saling berhubungan. Satu atau banyak siswa memiliki satu kelas. Satu siswa melakukan pembayaran satu atau banyak uang sekolah. Satu uang sekolah dikelola oleh satu karyawan.

\section{Hasil Implementasi Sistem}

A. Halaman Login

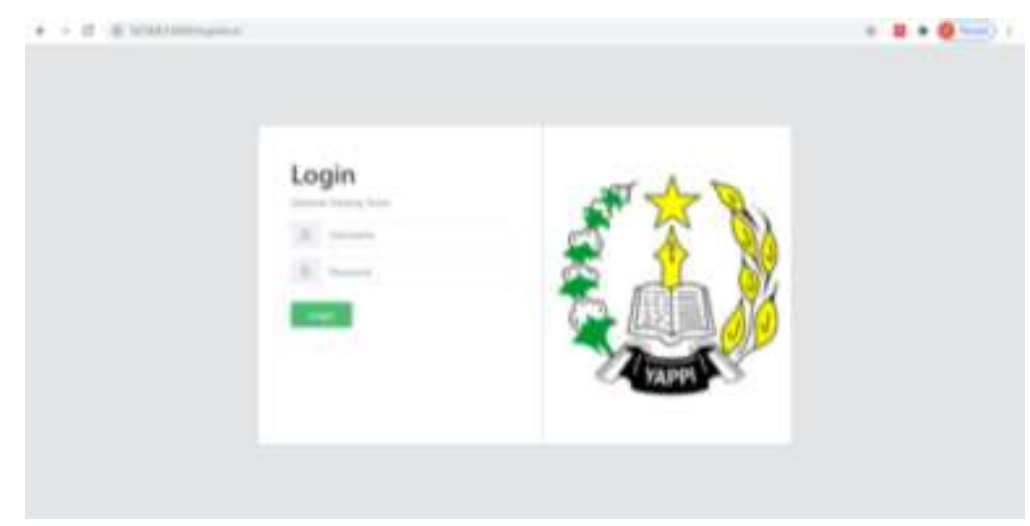

Gambar 6 Implementasi Halaman Login

Gambar 8 merupakan tampilan halaman login berfungsi untuk masuk ke sistem dengan cara memasukkan username dan password yang valid sesuai dengan akun masing-masing pengguna yang sudah terdaftar di sistem lalu klik tombol Login, maka sistem akan menampilkan halaman utama website. Proses MVC dalam halaman login yaitu dimana user melakukan permintaan akses login kemudian sistem akan melakukan proses pengerjaan dimulai dari pengelolaan database yang ada di bagian model, kemudian dilanjutkan ke proses untuk menampilkan data utama dalam tampilan 
aplikasi dan proses terakhir yaitu aksi login yang dilakukan sistem oleh perintah user.

B. Halaman Data Karyawan

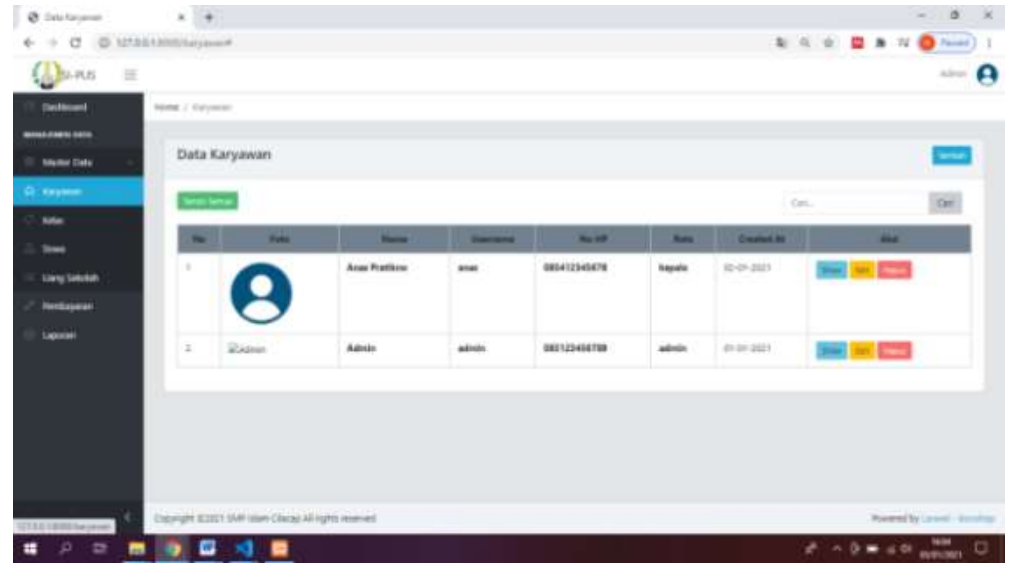

Gambar 7 Implementasi Halaman Data Karyawan

Gambar 9 merupakan tampilan halaman data karyawan yang berfungsi untuk mengelola data karyawan. Pada halaman ini digunakan oleh petugas yang dapat melakukan tambah, ubah dan hapus data. Proses MVC dalam halaman data karyawan yaitu dimana user melakukan permintaan akses data karyawan kemudian sistem akan melakukan proses pengerjaan dimulai dari pengelolaan database karyawan yang ada di bagian model, kemudian dilanjutkan ke proses untuk menampilkan data karyawan dalam tampilan aplikasi dan proses terakhir yaitu penerimaan input dari model karyawan dan view karyawan untuk menampilkan data karyawan yang dilakukan sistem oleh perintah user.

C. Halaman Data Siswa

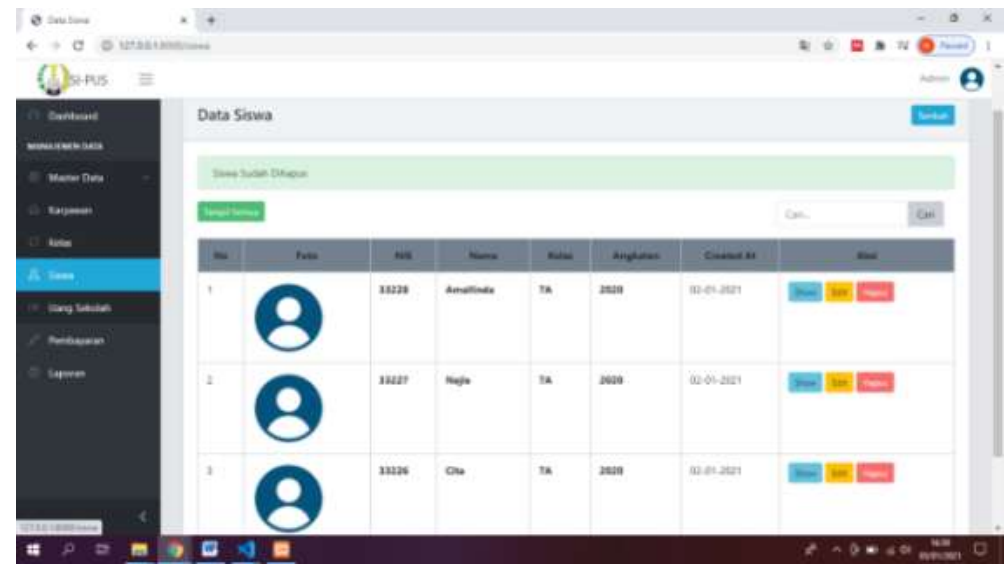

Gambar 8 Implementasi Halaman Data Siswa 
Gambar 10 merupakan halaman data siswa yang berfungsi untuk mengelola data siswa. Pada halaman ini digunakan oleh petugas yang dapat melakukan tambah, ubah dan hapus data. Proses MVC dalam halaman data siswa yaitu dimana user melakukan permintaan akses data siswa kemudian sistem akan melakukan proses pengerjaan dimulai dari pengelolaan database siswa yang ada di bagian model, kemudian dilanjutkan ke proses untuk menampilkan data siswa dalam tampilan aplikasi dan proses terakhir yaitu penerimaan input dari model siswa dan view siswa untuk menampilkan data siswa yang dilakukan sistem oleh perintah user.

D. Halaman Data Pembayaran

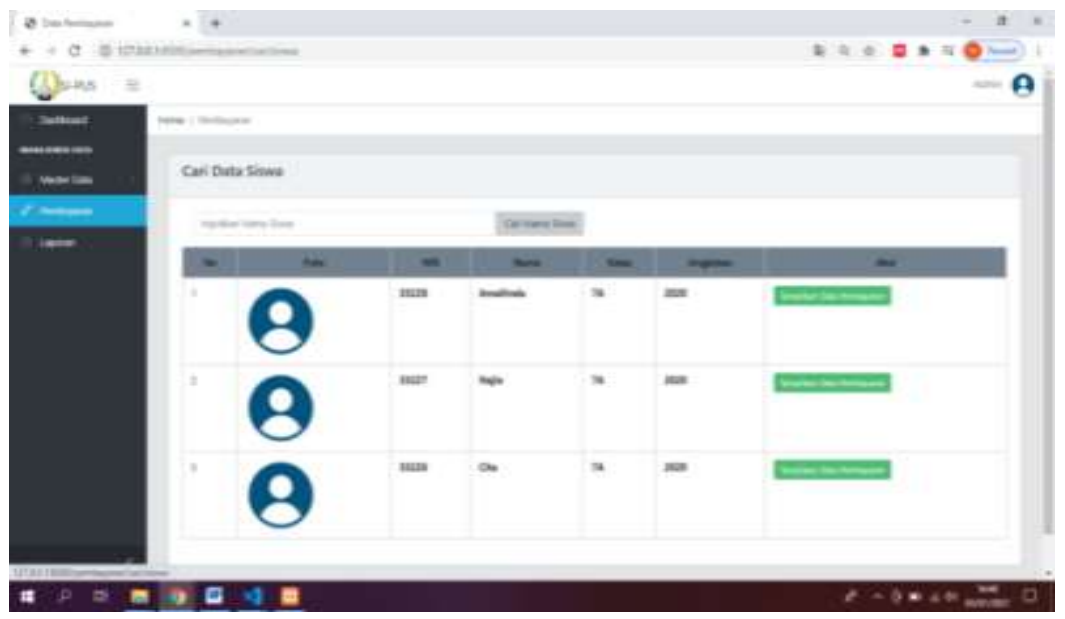

Gambar 9 Implementasi Halaman Data Pembayaran

Gambar 11 merupakan halaman data pembayaran yang berfungsi untuk mengelola data pembayaran siswa. Pada halaman ini digunakan oleh petugas yang dapat melakukan tambah dan ubah data. Proses MVC dalam halaman data pembayaran yaitu dimana user melakukan permintaan akses data pembayaran kemudian sistem akan melakukan proses pengerjaan dimulai dari pengelolaan database pembayaran yang ada di bagian model, kemudian dilanjutkan ke proses untuk menampilkan data pembayaran dalam tampilan aplikasi dan proses terakhir yaitu penerimaan input dari model pembayaran dan view pembayaran untuk menampilkan data pembayaran yang dilakukan sistem oleh perintah user. 
E. Halaman Data Laporan

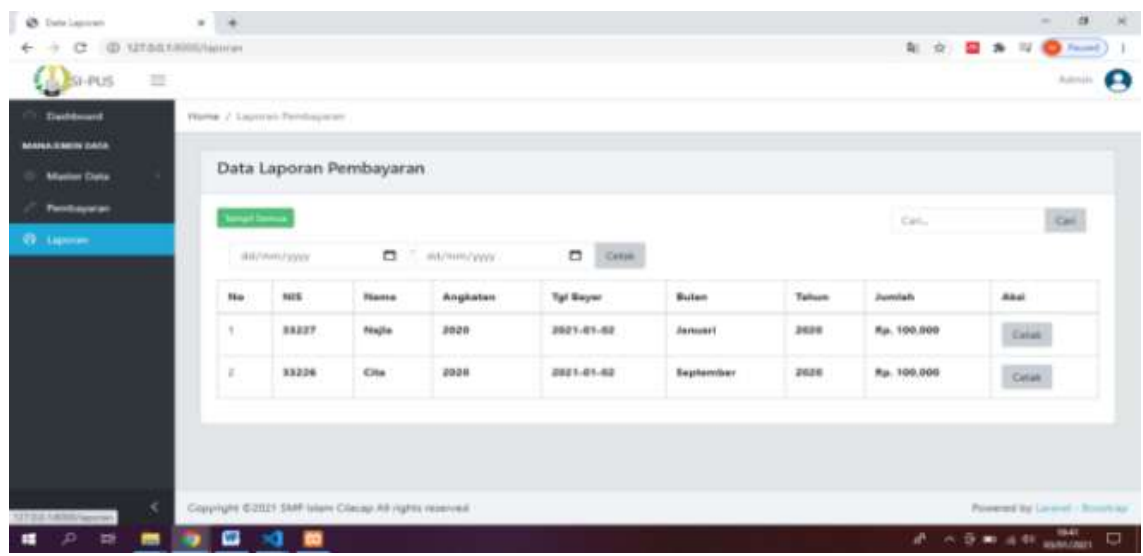

Gambar 10 Implementasi Halaman Data Laporan

Gambar 12 merupakan halaman data laporan pembayaran yang berfungsi untuk mengelola data laporan pembayaran. Pada halaman ini digunakan oleh petugas yang dapat melakukan pencarian dan cetak data laporan. Proses MVC dalam halaman data pembayaran yaitu dimana user melakukan permintaan akses data laporan kemudian sistem akan melakukan proses pengerjaan dimulai dari pengelolaan database pembayaran yang ada di bagian model, kemudian dilanjutkan ke proses untuk menampilkan data laporan dalam tampilan aplikasi dan proses terakhir yaitu penerimaan input dari model laporan pembayaran dan view laporan pembayaran untuk menampilkan data laporan yang dilakukan sistem oleh perintah user.

\section{F. Notifikasi SMS Gateway}

1) Sms Jatuh Tempo

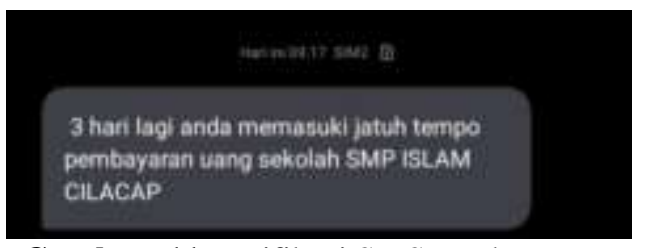

Gambar 11 Notifikasi SMS Jatuh Tempo

Gambar 13 merupakan notifikasi sms gateway berupa sms jatuh tempo yang dikirimkan oleh sistem jika siswa dalam 3 hari sebelum tanggal pembayaran belum melakukan pembayaran uang sekolah. Proses MVC dalam proses pengiriman sms jatuh tempo yaitu menggunakan 
model sms, view yang ada dalam halaman dashboard karyawan, controller sms (Kermite et al., 2012).

2) Sms Tagihan

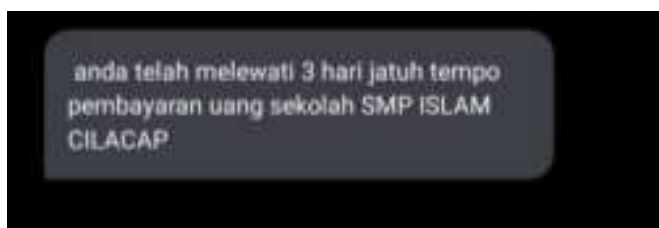

Gambar 12. Notifikasi SMS Tagihan

Gambar 13 merupakan notifikasi sms gateway berupa sms tagihan yang dikirimkan oleh sistem jika siswa setelah 3 hari tanggal pembayaran yang sudah ditentukan belum melakukan pembayaran uang sekolah.

\section{Pembahasan}

Hasil pengujian sistem berdasarkan uji responden yang telah dilakukan dengan menggunakan skala likert maka didapat jawaban dari 10 responden seperti pada Tabel 1.

Tabel 1. Hasil Kuesioner Pengujian Responden

\begin{tabular}{|c|c|c|c|c|c|c|c|}
\hline \multirow[t]{2}{*}{ No } & \multirow[t]{2}{*}{ Indikator } & \multicolumn{6}{|r|}{ Bobot } \\
\hline & & SK & $\mathrm{K}$ & $\mathrm{C}$ & $\mathrm{B}$ & $\mathrm{SB}$ & \\
\hline 1 & $\begin{array}{l}\text { Sistem memudahkan pengelolaan data } \\
\text { pembayaran uang sekolah }\end{array}$ & 0 & 0 & 1 & 4 & 5 & 88 \\
\hline 2 & $\begin{array}{l}\text { Sistem memudahkan pencarian data pembayaran } \\
\text { uang sekolah }\end{array}$ & 0 & 0 & 1 & 6 & 3 & 84 \\
\hline 3 & Sistem memudahkan pembuatan laporan & 0 & 0 & 2 & 4 & 4 & 84 \\
\hline 4 & $\begin{array}{l}\text { Sistem memudahkan mengetahui laporan } \\
\text { pembayaran uang sekolah }\end{array}$ & 0 & 0 & 2 & 4 & 4 & 84 \\
\hline 5 & $\begin{array}{l}\text { Sistem memudahkan mengetahui informasi } \\
\text { pembayaran uang sekolah }\end{array}$ & 0 & 0 & 1 & 4 & 5 & 88 \\
\hline & $\begin{array}{ll} & \text { Total : } \\
\end{array}$ & & & & & & 428 \\
\hline & Rata-Rata & & & & & & 85,6 \\
\hline
\end{tabular}

Hasil kuesioner keseluruhan dapat disimpulkan bahwa sistem dinilai cukup baik dalam mengatasi permasalahan di SMP Islam Cilacap. Berdasarkan hasil keseluruhan kuesioner untuk 10 responden bahwa $46 \%$ menyatakan sangat baik, 44\% menyatakan baik, dan $10 \%$ menyatakan cukup terhadap sistem ini. Hasil keseluruhan dengan perhitungan skala likert sebesar $86 \%$ masuk dalam kualifikasi Sangat Baik yang berarti berhasil. Grafik hasil kuesioner secara keseluruhan dapat dilihat pada Gambar 15. 


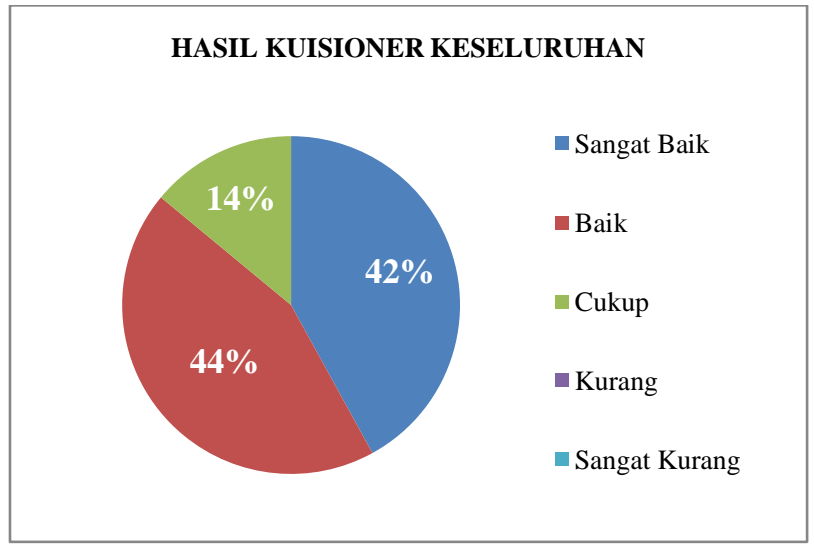

Gambar 13 Hasil Kuesioner Keseluruhan

\section{KESIMPULAN}

Penggunaan MVC dan notifikasi SMS Gateway dalam pembangunan sistem informasi pembayaran uang sekolah berhasil diterapkan dan mampu memberikan kemudahan dalam pembuatan sistem, hal ini dibuktikan berdasarkan hasil kuesioner yang diperoleh dari 10 responden bahwa 14\% menyatakan cukup, 44\% menyatakan baik dan $42 \%$ menyatakan sangat baik. Hasil keseluruhan dengan perhitungan skala Likert sebesar $86 \%$ masuk dalam kualifikasi Sangat Baik yang berarti berhasil dalam menyelesaikan permasalahan yang ada di SMP Islam Cilacap dengan mempermudah pengelolaan data pembayaran, penyampaian informasi pembayaran dan penyampaian data laporan.

\section{REFERENSI}

A.S., R., \& Shalahudin, M. (2015). Rekayasa Perangkat Lunak. Informatika Bandung.

Al-Bahra bin Ladjamudin. (2013). Analisis dan Desain Sistem Informasi (1st ed.). Graha Ilmu.

Bank Sentral Republik Indonesia. (2020). Sistem Pembayaran di Indonesia. Bank Sentral Republik Indonesia. https://www.bi.go.id/id/sistem-pembayaran/diindonesia/Contents/Default.aspx

Chasanah, N., Abda'u, P. D., \& Faiz, M. N. (2021). Implementasi Metode Waterfall dalam Sistem Informasi Knowledge Management untuk Digital Marketing. Infotekmesin, 12(1), 71-80. https://doi.org/10.35970/infotekmesin.v12i1.363 
Dayat, A. R., \& Angriani, L. (2017). Pemanfaatan Model-View-Controller (MVC) Dalam Rancang Bangun Sistem Informasi Rakornas Aptikom 2017. Seminar Nasional APTIKOM, November, 416-420.

Febriyati, N. A., Arnol, M. Y., Informasi, S., Online, P., \& Nugraha, B. W. (2020). Perancangan Sistem Informasi Penjualan Online Berbasis Web Design Sales Information System Online Based on Web on Batik. JIKO (Jurnal Infromatika Dan Komputer), 3(3), 153-158. https://doi.org/10.33387/jiko

Gupta, M., Rajnish, K., \& Bhattarcharjee, V. (2021). Predicting Software Cost Through Entity--Relationship Diagrams: An Empirical View. In V. Nath \& J. K. Mandal (Eds.), Nanoelectronics, Circuits and Communication Systems (pp. 561-567). Springer Singapore.

Kemdikbud RI. (2019). Sekolah Kita. Sekolah Data Kemdikbud.Go.Id. http://sekolah.data.kemdikbud.go.id/

Kermite, R. Y., Winarno, A., Rohmani, A., Informasi, S., Komputer, F. I., \& Nuswantoro, U. D. (2012). Perancangan Sistem Administrasi Sekolah Dengan SMS Gateway Berbasis Web Menggunakan Gammu Pada SMK LPI Semarang. $x, 15-27$.

Ma'rifati, I. S. (2015). Sistem Informasi Akuntansi Pendapatan Sumbangan Pembinaan Pendidikan (SPP) Pada SMU XYZ. Evolusi, 3(2), 1-4. https://doi.org/10.2311/evo.v3i2.212

Nugraha, S. A., \& Setiawan, R. (2017). Perancangan Sistem Informasi Pengolahan Administrasi Keuangan Sekolah Menengah Pertama Islam Terpadu Assalam Garut. Jurnal Algoritma, 13(2), 320-332. https://doi.org/10.33364/algoritma/v.13-2.320

Pressman, R. S., \& Maxim, B. R. (2019). Software engineering A Practitioner's Approach. In Kybernetes (Ninth Edit). McGraw-Hill. https://doi.org/10.1108/k.2000.06729iag.002

Rashkovits, R., \& Lavy, I. (2021). Mapping Common Errors in Entity Relationship Diagram Design of Novice Designers. International Journal of Database Management Systems, 13(1), 1-19. 
https://doi.org/10.5121/ijdms.2021.13101

Riana, D., Sanjaya, R., \& Kalsoem, O. (2018). Sistem Informasi Manajemen Laboratorium Patologi Anatomi Menggunakan Model MVC Berbasis Laravel Framework. Konferensi Nasional Sistem Informasi 2018 STMIK Atma Luhur Pangkalpinang, 8-9 Maret 2018, 8-9.

Sugiyono. (2012). Metode Penelitian Kuantitatif, Kualitatif dan R\&D. Alfabeta.

Tanjung, M. I. (2016). Analisis Dan Perancangan Sistem Informasi Berbasis Website Menggunakan Arsitektur Mvc Dengan Framework Codeigniter. Sekolah Tinggi Manajemen Informatika Dan Komputer Amikom.

Witanto, R., \& Solihin, H. H. (2016). Perancangan Sistem Informasi Penerimaan Siswa Baru Berbasis Web (Studi Kasus: SMP Plus Babussalam Bandung). Jurnal Teknologi Informasi Dan Elektronika (INFOTRONIK), 1(1), 54-63. https://doi.org/10.5281/zenodo.1495820

Wiyatno, T. N., Muhidin, A., \& Novian Dwi Prasetyo. (2020). Perancangan Sistem Informasi Pembayaran SPP Terpadu Menggunakan Metode Prototipe. JUSIKOM PRIMA (Junal Sistem Informasi Ilmu Komputer Prima), 4(1), 145-152. https://doi.org/10.34012/jusikom.v4i1.1207

Yesputra, Rolly, Marpaung Nasrun. (2018). Penerapan Arsitektur Model View Contoller (Mvc) Pada Sistem Informasi E-Skripsi Stmik Royal. In Jurnal Informatika Sains dan Teknologi (Vol. 3, Issue 2, pp. 281-290). 